\title{
Histological Study of the Circulatory System of Human Dental Pulp from Individuals under Local Anesthesia and Electro-acupuncture
}

\author{
By \\ Shigeru UEKI*, Yasutomo IWAI-LIAO, Kwang-Soon HAN and Yoshikage HIGASHI \\ Departments of Orthodontics* and Oral Anatomy, Osaka Dental University, 1-5-31, Otemae, Chuo-ku, Osaka 540, \\ Japan \\ - Received for Publication, September 6, 1994- \\ Key Words: Vessels, dental pulp, transmission electron microscopy (TEM)

\begin{abstract}
Summary: A transmission electron microscopic (TEM) study was conducted on dental pulp obtained from patients under acupuncture or infiltration local analgesia. It was difficult to differentiate lymphatic circulation in the dental pulp that received infiltration anesthesia, because the vessels were constricted, congested, and showed stasis and thrombosis. On the other hand, the dental pulp that received acupuncture showed normal arterioles, capillaries, and venules, as well as some lymph capillaries and small efferent lymphatic vessels that measured about $8 \mu \mathrm{m}$ and $100 \mu \mathrm{m}$ in diameter, respectively. The lymphatic endothelial walls had many intercellular gaps, an imperfect basal lamina, and a few discontinuous pericytes. Between the openings in the lymphatic vessels, there were bundles of junctional filaments extending towards the dental pulp connective tissue. Therefore, the lymphatic system, which contains mainly B-3- $\alpha$ capillaries, is a leaky tissue for regulating fluid in the dental pulp.
\end{abstract}

The pulp organ is extensively vascularized and has a more rapid blood flow than in most areas of the body. But the presence of lymphatic supply, another circulatory system which is believed always to accompany the blood vascular system in many tissues and organs, in the dental pulp is still under dispute (Mori 1979; Torneck 1980; Avery 1991).

The literature contains some light microscopic (LM) studies of lymphatic vessels in the dental organ. These studies have demonstrated the lymphatic vessels to be thin discontinuous endothelial walls having imperfect basement membrane and containing no red blood cells in their lumen (Balogh and Boros 1957; Isokawa 1960; Bernick and Patek 1969; Bernick 1977a; Bernick 1977b; Torneck 1980). But a transmission electron microscopic (TEM) study on dental pulp from various animals has denied the presence of lymph vessels, and pointed out that the lymphatic vessel-like structures viewed at the LM level were actually venules (Takada 1973).

Lidocaine chloride containing epinephrine is an analgesic solution usually used in dental treatment. Direct observation of the effects of analgesics and epinephrine upon the rat living dental pulp under a research microscope have elucidated temporary disturbance and irreversible changes in the blood flow (Photo and Scheinin 1961). However, another study on extracted human teeth under local or general anesthesia or with no anesthesia has demonstrated the same immediate histological changes, but no permanent damage to pulp tissue, and mentioned that no distinct histological differences were observed in the specimens (Langeland 1962).

On the other hand, acupuncture analgesia is clinically useful in pain control and relief of symptoms of dental pulpal inflammation, which is a complicated tissue reaction usually involving both the blood and lymph vascular systems. We extracted healthy teeth under acupuncture, and obtained dental pulp that was devoid of analgesics.

This present TEM study was thus undertaken to compare the histology of normal human dental pulp under the influences of acupuncture and local anesthesia. We also attempted to observe the lymph vascular system of teeth that had received minimal tissue damage and thus showed the best possible preservation.

\section{Materials and Methods}

Premolars that had completed apical closure were removed for orthodontic purposes from healthy teenagers under the infiltration of local anesthetics containing 3\% lidocaine chloride and 1:80,000 epinephrine or electro-acupuncture. The Huku (Li-4) point of the Chinese medriatic map was punctured for a duration of 5 minutes. 
The teeth were snapped into halves after a groove had been cut with a diamond disc in a chilled $0.1 \%$ sodium cacodylate buffer solution at $4^{\circ} \mathrm{C}$. The samples were immediately immersed in buffered fixative solution containing $2 \%$ paraformaldehyde and $2.5 \%$ glutaraldehyde (pH 7.2, $4^{\circ} \mathrm{C}, 1 \mathrm{hr}$ ) (Karnovsky 1965). The samples were then rinsed overnight in the buffer solution, postfixed in buffered $1 \%$ osmium tetroxide for one hour, decalcified with 0.5 M EDTA for two weeks, washed in the buffer solution for another two weeks, dehydrated through a graded series of ethyl alcohol, and embedded in Epon 812 following conventional methods. Ultrathin sections of the pulp tissues were prepared with glass knives mounted on an LKB ultrotome, picked up on grids, stained with uranyl acetate and lead citrate, and then examined and photographed under an HU-800 TEM (Reynolds 1963; Stempak 1964).

\section{Findings}

The present TEM study on the tissue response of the blood vascular microcirculation in dental pulp with particular emphasis on the effects of local anesthetics containing lidocaine chloride and epinephrine showed constriction of the capillaries and arterioles, congestion, stasis, and thrombosis of venules, and edematous changes in both the odontoblastic and sub-odontoblastic layers; although some odontoblasts were aspirated into the dental tubules, the pulpodentinal membrane remained intact (Figs. 1a-2b).

In contrast, specimens obtained from individuals who had received acupuncture had capillaries, arterioles, and venules measuring $7 \mu \mathrm{m}, 12$ to $50 \mu \mathrm{m}$, and 50 to $90 \mu \mathrm{m}$ in diameter, respectively. Many capillaries were observed in the dental pulp connecting the arterioles and venules (A-V shunts), indicating an increase in circulatory bypass. In addition, the occurrence of many vesicles in the pericytes and endothelial cells, as well as the migration of lymphocytes and the appearance of mast cells in the pulp tissue, seemed to indicate an active circulation related to defensive reactions induced by the lowfrequency, electric-stimulation acupuncture (Figs. $3 a$ and $b$ ).

The pulp contained many proper cells having many long and slender cellular processes and matricial collagen fibrils. Both myelinated and unmyelinated nerve fibers were observed in the tissue either under local anesthesia or acupuncture. The endings of the unmyelinated nerves approximating the arterioles were swollen and included some electron-dense vesicles. The nerve endings in the predentine contained many vesicles, vacuoles, and large mitochondria attached to odontoblastic processes by tight junctions (Figs. 4a and b).

Cross sections showed the venules were ovoid with their endothelial cells curved towards the lumen. Their walls were fenestrated and perforated, although the basement lamina (basal lamina) was complete and continuous (Figs. 5a and b). The arterioles, however, were round and surrounded by associated pericytes that shared the same basement membrane. The pericyte cytoplasm contained many small vesicles that were for the most part concentrated on the side opposite the nerve endings. However, a direct synapse relation between the nerves and pericytes was not demonstrated by TEM in the present study (Figs. 3a and 6a).

The blood vascular microcirculation was composed of continuous capillaries with junctional complexes mainly of the macula adherens type. They were surrounded by a complete basal lamina. TEM also showed that, particularly in the arterioles, there were club-like structures protruding from the body of endothelial cells towards the lumen (Fig. 6a and $b$ ).

In contrast, there were some capillaries and venulelike structures partially lacking intercellular junctional complexes. They abutted, overlapped, and interdigitated with adjacent endothelial cells to form a thin vascular wall with many gaps. They were surrounded in places by a discontinuous basal lamina and a few pericytes. Moreover, the endothelium gave off many short, tortuous, and branching cellular projections protruding towards the lumen. There was coagulated plasma in the lumen but no blood corpuscles (Figs. 7a-11a). Between the gaps, particularly in the depressed areas, and around the periphery of small external protuberances of the vascular wall, the reticular lamina of the basement membrane sent out bundles of fine filaments and collagen fibrils that merged with the surrounding dental pulp connective tissue (Figs. 7b-14).

\section{Discussion}

Studies on vascular microcirculation have indicated that arterioles measuring 20 to $100 \mu \mathrm{m}$ in diameter are surrounded by smooth muscles and elastic fibers, while small arterioles measuring about $150 \mu \mathrm{m}$ have two to three layers of muscle cells. These muscle cells are sensitive to circulating humoral agents. Furthermore, meta-arterioles serve as stop-corks controlling the amount of blood perfusing the capillary bed. Small and large venules measuring 15 to $20 \mu \mathrm{m}$ and $50 \mu \mathrm{m}$ to $200 \mu \mathrm{m}$ in diameter, respectively, are also sensitive to histamine and serotonin, and are highly permeable. However, only large venules are partially surrounded by smooth muscle cells along 
their long axis (Majno and Palade 1961; Majno et al. 1961; Bloom and Fawcett 1994; Ekblom and Hansson 1984).

Vascular capillaries are morphologically differentiated into continuous, fenestrated, and sinusoidal types. Studies have shown that these capillaries are usually 7 to $9 \mu \mathrm{m}$ in diameter and are composed of 1 to 5 endothelial cells that are particularly sensitive to humoral agents such as bradykinin. Bradykinin increases the passage of macromolecules from the capillary bed into the tissue fluid. In addition, the club-like structure of the endothelial cells seems related to the ciliary movement that propels the contents in the vascular lumen (Mohamed et al. 1973; Bloom and Fawcett 1994; Andrew et al. 1980).

Many studies on microcirculation have indicated that two pore systems transport blood cells and plasma containing molecules of various sizes in the capillaries. One is a pathway through the junctional complexes for small particles measuring about $40 \AA$ in diameter, and the other is through channels and fenestrations in the cytoplasm and walls for transporting macromolecules measuring more than $800 \AA$ (Bennet et al. 1959; Palade 1961; Florey 1968; Palade et al. 1979; Cho and De Bruyn 1981; Bloom and Fawcett 1994).

Our study showed the same results as others (Kato 1966; Takada 1971; Mori 1979). In addition to this blood vascular system, there were abutted, overlapped and interdigitated endothelial cells that formed irregular capillaries and vessels of various sizes having many openings due to a partial lack of intercellular junctional complexes. Moreover, they were surrounded by an imperfect basal membrane, and had anchoring filaments to control the gaps in the vascular wall. These structures had many short and small endothelial projections pointing into the vascular lumen, but no valve-like structures. These findings indicated lymph capillaries and small efferent ducts in the dental pulp (Kato 1966; Carle-Smith 1967; Cho and De Bruyn 1979; Mori 1979; Helge 1975).

The imperfect wall and gap-controlling junctional filaments of the lymph capillaries suggest a high permeability of the dental pulp lymphatic circulation, which is important for regulation and balancing of the extracellular environment of the pulp tissue. However, it is reported that $10 \%$ of the tissue fluid drains into the lymphatic system while $90 \%$ goes to the veins (Carley-Smith 1967; Helge 1975; Cho and De Bruyn 1979; Andrew et al. 1980).

The present study on the dental pulp of teeth taken from individuals under acunpuncture anesthesia showed a more active vascular and lymphatic circulation than was found in studies where local anesthetics were used. Further study should be carried out on the distribution of the lymphatic circulation.

\section{References}

1) Andrew CF, Cho $Y$ and De Bruyn PPH. The structure of the sinus wall of the lymph node relative to its endocytic properties and cell passage. Am J Anat 1980; 157:265-284.

2) Avery JK. Pulp. In: Orban's Oral Histology and Embryology, 11th ed., (Bhaskar, SN ed.) 141-181, C.V. Mosby, Saint Louis, 1991.

3) Balogh $K$ and Boros S. Experimentell Untersuchunge uber die Lymphzirkulation der Pulpa. Osterr Z Stomatol 1957; 54:393-408.

4) Bennet HS, Luft JH and Hampton JC. Morphological classifications of vertebrate blood capillaries. Am J Physiol 1959; 196:381-390.

5) Bernick S and Patek PR. Lymphatic vessels of the dental pulp in dogs. J Dent Res 1969; 48:959-964.

6) Bernick S. Lymphatic vessels of the human dental pulp. J Dent Res 1977a; 56:841-849.

7) Bernick S. Morphological changes to lymphatic vessels in pulp inflammation. J Dent Res 1977b; 56:841-849.

8) Bloom W and Fawcett DW. A Textbook of Histology. 12th edn, 368-408, Chapman \& Hall, New York - London, 1994.

9) Carley-Smith JR. An electron microscopical study of the passage of ions through the endothelium of lymphatic and blood capillaries, and through the mesothelium. Q Jl Exp Physiol 1967; 52:105-113.

10) Cho Y and De Bruyn PPH. The endothelial structure of the postcapillary venules of the lymph node and the passage of lymphatic across the venule wall. Am J Anat 1979; 69: $13-21$.

11) Cho $Y$ and De Bruyn PPH. Lymphocytes through the walls of the smooth-surfaced squamous endothelial venules in the lymph node: evidence of the direct entry of lymphocytes into the blood circulation of the lymph node. J Ultrastruct Res 1981; 74:259-266.

12) Ekblom A and Hansson P. A thin-section and freezefracture study of the pulp blood vessels in feline and human teeth. Archs Oral Biol 1984; 29:413-424.

13) Florey $L$. The missing link, the structure of some type of capillary. Q JI Exp Physiol 1968; 53:1-5.

14) Helge K. Fenestrated blood capillaries and lymphatic capillaries in rat skeletal muscle. Cell Tissue Res 1975; 63:169174.

15) Isokawa S. Uber des Lymphsystem des Zahnes. Z. Zellforsch $1960 ; 52: 140-149$.

16) Karnovsky MJ. A formaldehyde-glutaraldehyde fixative of high osmolarity for use in electron microscopy. J Cell Biol 1965; 27:137A.

17) Kato $F$. The fine structure of lymphatics and the passage of China ink particles through their walls. Part 1 . The structure of the lymphatics of the cattle lung and the passage of China ink particles through their walls. Nagoya Med 1966; 12:221252.

18) Langeland $K$. Effects of local anesthetics on pulp tissue. Dent Prog 1962; 3:17/13-22/18.

19) Majno $G$ and Palade GE. Studies on inflammation. I. The effect of histamine and serotonin on vascular permeability: an electron microscopic study. J Biophysic Biochem Cytol 1961; 11:571-605.

20) Majno G, Palade GE and Schoefel GI. Studies on inflammation. II. The site of action of histamine and scrotonin along the vascular tree: a topographic study. J Biophysic 
Biochem Cytol 1961; 11:607-626.

21) Mohamed AH, Waterhouse JP and Friederici HHR. The fine structure of gingival terminal vascular bed. Microcircular Res 1973; 6:137-152.

22) Mori K. Methods for morphologic study on the peripheral lymphatic vessels -fine structures and their positional relationship to the blood vessels-. Acta Anat Nippon 1979; 54:1-20. (Japanese)

23) Palade GE. Blood capillaries of the heart and other organs. Circulation 1961; 24:368-384.

24) Palade GE, Simionescu $M$ and Simionescu N. Structural aspects of the permeability of the microvascular endothelium. Acta Physiol Scan (suppl), 1979; 463:11-32.

25) Photo $M$ and Scheinin $A$. Effects of local anesthetic solutions on the circulation of the dental pulp. Int Dent J 1961; 11:
227-232.

26) Reynolds ES. The use of lead citrate at high $\mathrm{pH}$ as an electron-opaque stain in electron microscopy. J Cell Biol 1963; 17:208.

27) Stempak JC and Ward RT. An improved staining method for electron microscopy. J Cell Biol 1964; 22:267.

28) Takada $M$. The ultrastructure of lymphatic valves in rabbit and mice. Am J Anat 1971; 132:207-218.

29) Takada M. Light and TEM study on blood vessels in the dental pulp -in particular on the existence of the lymph vessels and the specific histology of the venules-. Acta Anat Nippon 1973; 48:118-134.

30) Torneck CD. Dentin-pulp complex. In: Oral Histology; Development, Structure, and Function, (Ten Cate AR ed.) 140-181, C.V. Mosby, Saint Louis, 1980.

\section{Explanation of Figures}

\section{Plate I}

Fig. 1. Dental pulp under local anesthesia.

1a. Constriction of blood capillaries (BC) and congestion of venules (V) are observed $(\times 3,500)$.

1b. A capillary with a small lumen $(\mathrm{Lu})$ is completely embedded in a continuous basement membrane $(\mathrm{BM}, \times 9,300)$.

1c. An arteriole (A) is strongly compressed by its associated pericytes (PC, $\times 4,600)$.

Fig. 2. TEM showing the odontoblast $(\mathrm{Ob})$ layer and pulpodentinal membrane in dental pulp from a patient who had received local anesthesia.

2a. The junctional complexes (JC) are intact, and the putative Korff's fiber (KF) runs between the surrounding cells $(\times 20,000)$.

2b. Aspiration of an $\mathrm{Ob}$ into the predentine $(\mathrm{Pd})$ is evident $(\times 2,400)$.

Fig. 3. Microcirculation in the dental pulp from individuals who received acupuncture.

3a. Many vesicles (arrows) in the Pc and endothelial cells indicate the cells were affected by humoral agents $(\times 23,000)$

3b. A defensive cell (arrowhead) has left the BM aneurysmal pocket (arrow) of a venule $(\times 2,300)$. 


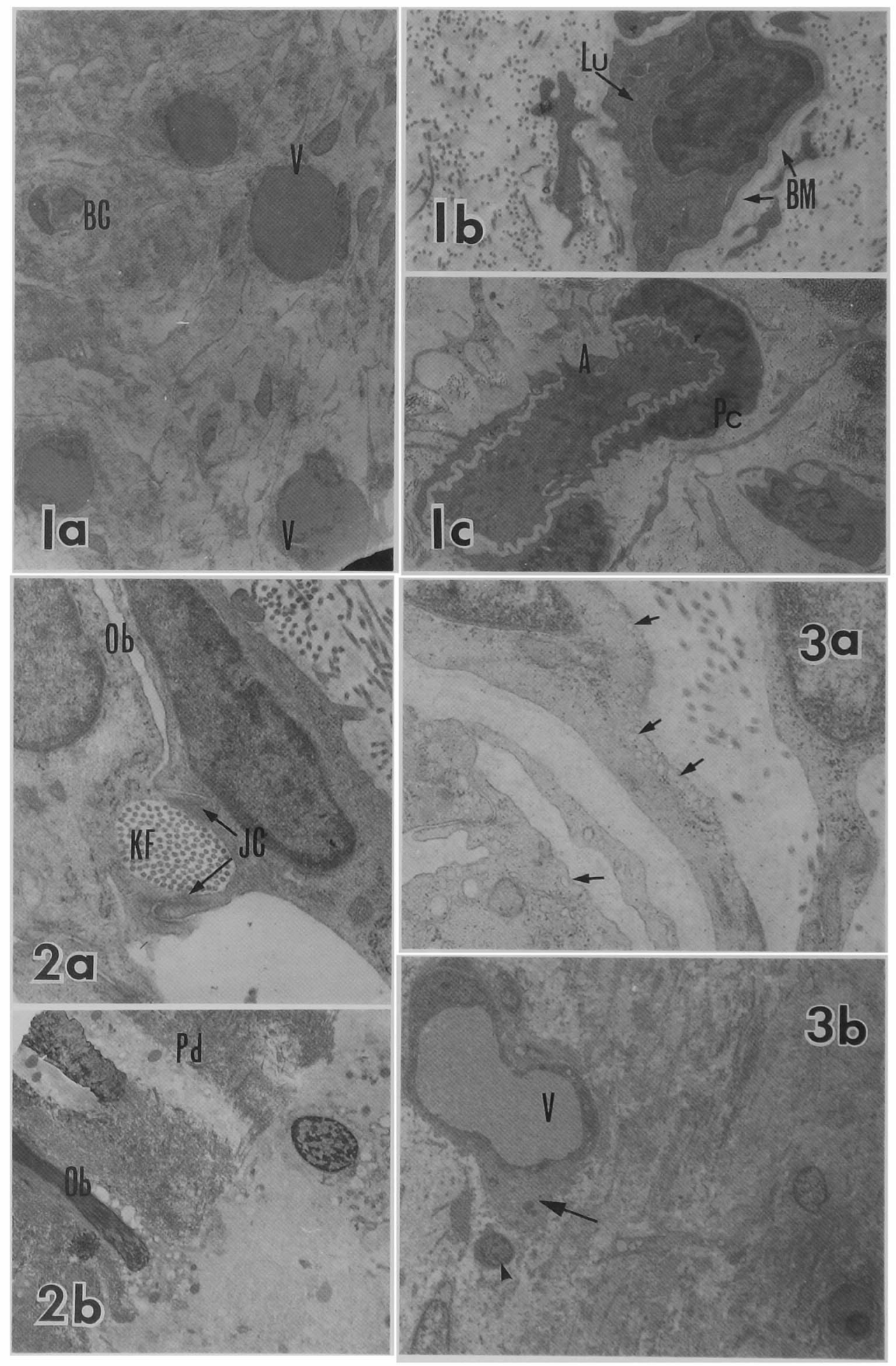




\section{Plate II}

Fig. 4. Nerve fiber (NF) in the dental pulp.

4a. An unmyelinated NF gives off a secretory granule (arrow)-containing ending that lies next to an arteriole $(\times 6,000)$.

4b. An NF located in the vicinity of an $\mathrm{Ob}(\times 35,000)$.

Fig. 5. TEM of a venule (V).

5a. General view of the A-2-type vessel $(\times 3,000)$.

5 b. Arrows indicate fenestrations in the endothelial wall. The BM is continuous $(\times 7,000)$.

Fig. 6. Photo showing an arteriole (A).

$6 \mathrm{a}$. The vessel has a complete continuous $\mathrm{BM}(\times 3,500)$.

6 b. Higher magnification showing a club-like structure (arrow) of the endothelial cell $(\times 3,000)$.

Fig. 7. TEM showing microcirculation in the dental pulp affected by acupuncture.

7 a. Note lymph capillary (LC) in the tissue $(\times 1,200)$.
7 b. Higher magnification of the B-3- $\alpha$ LC $(\times 9,300)$. 

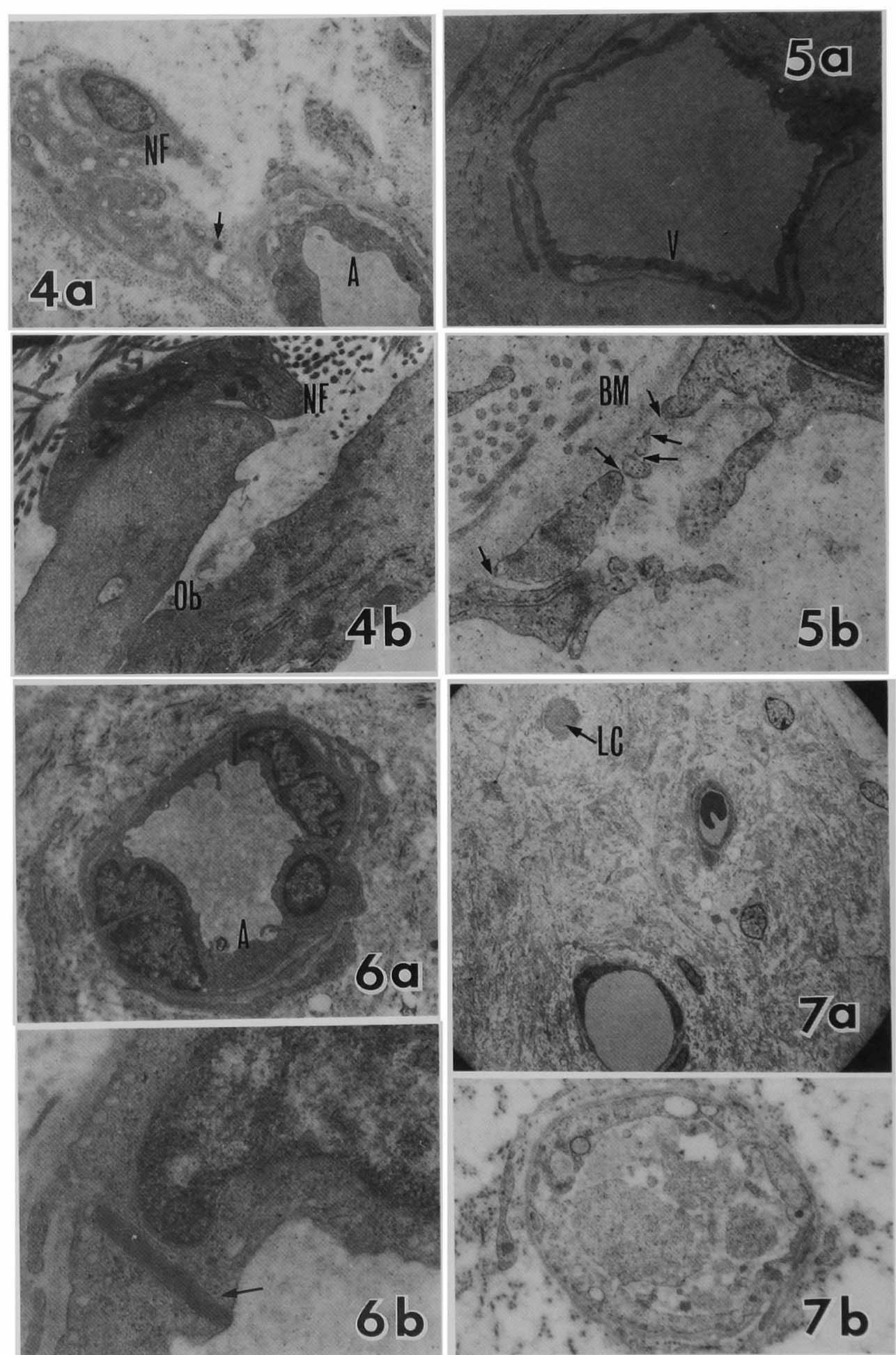


\section{Plate III}

Fig. 8. LC endothelium containing many vessels and vacuoles.

The endothelial cells overlap to form numerous gaps in the wall (arrows, $\times 11,000$ ).

Fig. 9. Endothelial cells that have abutted, overlapped, and interdigitated (arrows).

The reticular lamina (arrowheads) of the BM is distributed on the periphery of the basal lamina $(\times 29,000)$.

Fig. 10. Anchoring (junctional) filaments (JF) are developed in the intercellular gap regions of the LC $(\times 35,000)$.

Fig. 11. Reticular lamina (arrows) of an efferent lymph capillary extends into the surrounding connective tissue $(\times 5,600)$.

Fig. 12. JF in the opening and nearby the short external projections of an LC $(\times 3,400)$.

Fig. 13. Details of the JF originating from an intercellular gap in the interdigitated endothelial cells.

The JF contains fine fibrils $(\times 14,000)$.

Fig. 14. JF (arrow) merges into the matrix of the pulp tissue (TEM, $\times 11,000)$. 
Plate III
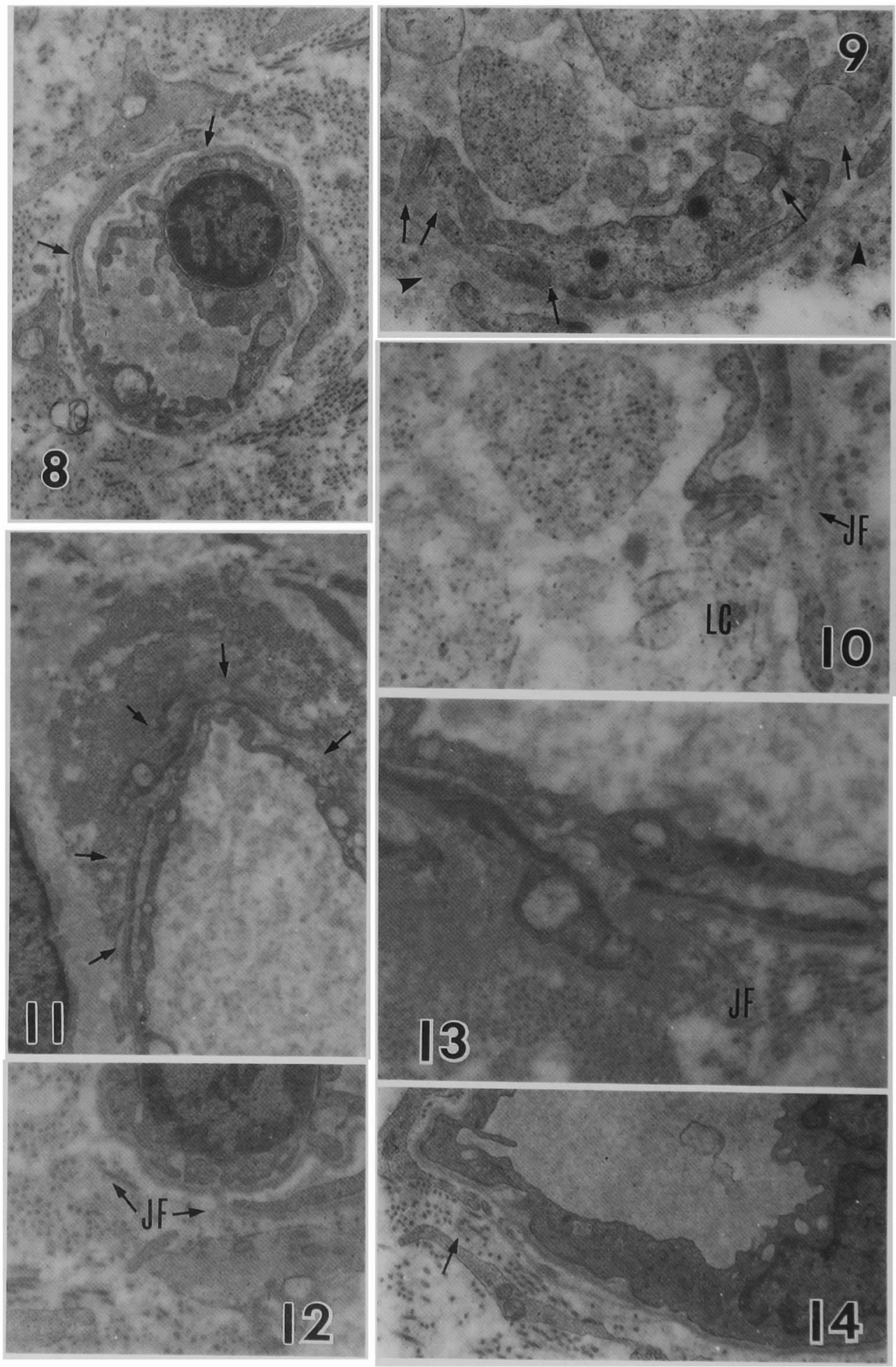